\title{
The Possibility of Using Zinc Oxide Nano Particles for Treatment of Bovine-Subclinical Mastitis, in Vitro Antibacterial Activity
}

\author{
Zerihun Beyene Rupita Ghosh \\ Koneru Lakshmiah Education Foundation, Green Fields, Vaddeswaram, \\ Guntur District, Andhra Pradesh, India 522502
}

\begin{abstract}
Bovine mastitis is an inflammation of mammary gland parenchyma in cows. It is caused by multiple pathogens that result in economic losses because of the reduction in milk production and poor quality of the milk. It is commonly caused by bacteria that multiply in the mammary gland and regional lymph nodes, damaging the mammary parenchyma. The present study focuses on the bovine mastitis treating capacity of zinc oxide nanoparticles by examining in vitro antibacterial activity, MIC and MBC against pathogens isolated and identified from sub-clinical mastitis in dairy cows. Zinc oxide nanoparticles were synthesized both chemically and green methods from a plant extract of Coriandrum sativum and characterized for phase and microstructural analysis. The milk sample from subclinical mastitis cows was collected from the veterinary hospital. The bacteriological examination revealed the presence of $S$. aureus and $E$. coli. The antibacterial activity of the zinc oxide nanoparticle was evaluated at $650,850,1300,1700,1950$ and $2500 \mu \mathrm{g} / \mathrm{ml}$ concentrations and the minimum inhibitory concentration was found to be $650 \mu \mathrm{g} / \mathrm{ml}$ and $850 \mu \mathrm{g} / \mathrm{ml}$ for S.aureus and E.coli respectively, and minimum bactericidal concentration was $650 \mu \mathrm{g} / \mathrm{ml}$ and $1700 \mu \mathrm{g} / \mathrm{ml}$ for $S$. aureus and E. coli respectively.
\end{abstract}

Keywords: Antibacterial activity, bovine subclinical Mastitis, Coriandrum sativum, chemical synthesis, green synthesis, minimum inhibitory concentration, minimum bactericidal concentration, zinc oxide nanoparticles

DOI: $10.7176 / \mathrm{CMR} / 11-10-01$

Publication date: December $31^{\text {st }} 2019$

\section{Introduction}

The world human population is expected to reach 9.4 billion by 2050 (Lutz et al. 2017). Food from animal sources is an important aspect of the human diet globally and it contributed to the development and the eradication of poverty in human society. To meet the increasing food demand of the world population animal health plays a crucial role (Lutz et al. 2017; Sun 2018). Animal health has a major role in food security for human consumption especially in developing countries (Kampeerapappun 2019; Xie et al. 2011).

Bovine mastitis is mammary gland parenchyma inflammation and it is one of the important diseases in the dairy industry. It is the most complex dairy cow disease which is negatively affecting milk production. It is commonly caused by bacteria in dairy cattle and characterized by the chemical, physical and bacteriological changes occurring in the milk(Gunay and Gunay 2008; Sharma et al. 2017). In the dairy industry, it is a disease with an important economic impact which results in huge losses (Bradley et al. 2007). The majority of antibiotics used in these industries are applied for the prevention and control of mastitis (Memon et al. 2013; Stevens et al. 2019). However, drugs used for control, prevention and treatment of mastitis are not effective currently, this is mainly due to the development of resistance to wide range antibiotics used, as these drugs have been used for a long period of time and other possible causes (El-Jakee et al. 2013; Memon et al. 2013; Raguvaran et al. 2015), (Bradley et al. 2007; Stevens et al. 2019) .

Nanotechnology is being applied in a variety of fields like medicine, food, and agriculture. It is used to produce nano-sized particles that have different physical, optical and mechanical properties from their bulk (Xie et al. 2011). In the field of medicine, nanotechnology is being implemented for drug delivery, diagnostics and disease treatment (Hassan et al. 2014; Kampeerapappun 2019). Zinc oxide ( $\mathrm{ZnO}$ ) nanoparticle is one of the recent outcomes of nanotechnology. The Food and Drug Administration (FDA) of the U.S has listed Zinc oxide (ZnO) as Generally Recognized As Safe" (GRAS) (Xie et al. 2011). ZnO has been incorporated in materials used for packaging of fish, meat and other foods to prevent spoilage and enhancement of preservation. Nanosized ZnO particles have antibacterial activities against a wide range of bacteria than their bulk counterparts. This is due to its small size and high surface to volume ratio of nanoparticles which improves interaction with bacteria. Zinc nanoparticle also has selective toxicity against bacteria (Reddy et al. 2007; Xie et al. 2011).

The most common pathogens responsible for subclinical bovine mastitis are S. aureus, S. agalactiae, and other Streptococcus species and Coliforms (Sharma et al. 2017). Antibiotic resistance in bacterial and fungal species is significantly increasing which causes diseases like mastitis incurable using antibiotics. This condition triggered for other options, one of which is the use of metals as antibiotics against bacterial and fungal agents (Mohanraj 2017).

Different researches have been done to develop new antimicrobial agents in order to combat antimicrobial resistance microorganisms as an alternative to existing drugs (Mohanraj 2017). Current studies are showing that 
different nanoparticles have antibacterial and antifungal activities, but having minimal effects on human and animal cells (Jin et al. 2009; Sharma et al. 2007). When metal oxides are synthesized in the nano range, they exhibit unique properties which are size, chemical composition and surface chemistry dependent (Kumar et al. 2019). The antimicrobial property of zinc oxide $(\mathrm{ZnO})$ nanoparticles (NPs) is extensively studied among metal oxide nanoparticles (Jones et al. 2008). Activities of a wide range of bacteria have been reduced by zinc oxide. The antimicrobial properties of zinc oxide are significantly increased at the nanoparticle level (Jin et al. 2009; Jones et al. 2008). Zinc oxide ( $\mathrm{ZnO}$ ) nanoparticles (NPs) possess antibacterial, antifungal and anti-inflammatory properties and facilitate the healing of both acute and chronic wounds (Kumar et al., 2019; Sharma, Maiti, \& Sharma, 2007). Therefore, the current work was undertaken to synthesize ZnO NPs using both green and chemical methods, characterize and investigate the subclinical mastitis treating capacity of the nanoparticle by examining its invitro antibacterial activities against pathogens isolated and identified from mastitis dairy cow.

\section{Materials and methods}

\subsection{Collection of milk samples}

Dairy cows with clinical signs of mastitis were diagnosed for subclinical mastitis by a certified veterinarian from a veterinary hospital in Vijayawada city, Andhra Pradesh, India. A total of ten milk samples from ten confirmed subclinical mastitis dairy cows was aseptically collected. In brief, each teat was cleaned, disinfected using a $0.5 \%$ iodine solution and dried with a sterile paper towel. The milk sample of about $15 \mathrm{ml}-20 \mathrm{ml}$ was stripped from teats to the sterile test tube. Then each tube was labeled and transported in an ice box to the microbiology laboratory at KL University.

\subsection{Bacteriological examination}

Standard bacteriological analytical methods were used to recover bacterial isolates from subclinical bovine mastitis in the milk sample. Isolation of bacterial strain was conducted according to the National Mastitis Council procedures (Middleton et al. 2014). Blood agar (HiMedia, India) in which sheep red blood cell (5\%) was added and MacConkey agar (HiMedia, India) were prepared and loop full of the milk sample was streaked on it. The plates were incubated at $37^{\circ} \mathrm{C}$ for $24-48 \mathrm{~h}$ aerobically. The plates were inspected for colony morphology and characteristics of hemolysis after 24 and $48 \mathrm{~h}$. The morphological characteristic of the bacteria was identified by Gram's Method of staining and colony morphology. The catalase test and coagulase test were used to identify the strain in addition to, the pattern of hemolysis and colony morphology.

\subsection{Zinc nanoparticles preparations}

The synthesis of ZnO NPs was carried both chemically and by green synthesis methods using a zinc precursor in an alkaline medium. All chemicals used throughout this work were purchased from Merck and, are of analytical grade. The input parameters of the synthesis process were identified and optimized. Then the synthesis and characterization studies were performed at optimum input conditions.

\subsection{Preparation of plant extract}

The Coriandrum sativum plant leaf was used as a reducing and capping agent to synthesize ZnO NPs as indicated in (Goutam et al. 2017). The fresh plants were collected from a local market in Vijayawada city, Andhra Pradesh, India. The leaves were surface cleaned using distilled water for about three times to remove the minor organic contents from the surface of the leaves. Then $10 \mathrm{~g}$ of the leaf was mixed with $200 \mathrm{ml}$ of distilled water and heated at a temperature of $70{ }^{\circ} \mathrm{C}$ for about $30 \mathrm{~min}$ to get the plant extract. After boiling, the liquid extract is separated through filtering and then the extract was cooled down for $4 \mathrm{~h}$ at room temperature.

\subsection{Green synthesis of $\mathrm{ZnO}-\mathrm{NPs}$}

$0.2 \mathrm{M}$ of Zinc acetate dihydrate solution $\left(\mathrm{Zn}\left(\mathrm{CH}_{3} \mathrm{COO}\right)_{2} \cdot 2 \mathrm{H}_{2} \mathrm{O}\right)$ was prepared and the Coriandrum sativum plant extract was added to the solution in $1: 1(\mathrm{v} / \mathrm{v})$ ratio. This mixture was stirred and heated at $70{ }^{\circ} \mathrm{C}$ and sodium hydroxide $(\mathrm{NaOH})$ is added drop by drop to it till light yellow color precipitate was formed. The yellowish precipitate was centrifuged at $5000 \mathrm{rpm}$ for $20 \mathrm{~min}$ and washed three times with distilled water followed ethanol. Then the precipitate was dried in an oven and finally calcinated at $500{ }^{\circ} \mathrm{C}$ for $2 \mathrm{~h}$.

\subsection{Synthesis of $\mathrm{ZnO}$ NPs by precipitation method}

$\mathrm{ZnO}$ NPs were synthesized by direct precipitation method using zinc acetate dihydrate solution and potassium hydroxide $(\mathrm{KOH})$ as precursors and a precipitating agent respectively as described elsewhere (Ghorbani et al. 2015). In brief, an aqueous solution of $0.2 \mathrm{M} \mathrm{Zn}\left(\mathrm{CH}_{3} \mathrm{COO}\right)_{2} \cdot 2 \mathrm{H}_{2} \mathrm{O}$ and $0.4 \mathrm{M} \mathrm{KOH}$ solutions were prepared with deionized water. The $\mathrm{KOH}$ solution was slowly added into Zinc acetate dihydrate solution at room temperature under vigorous stirring. This resulted in the formation of a white suspension. The white product was centrifuged at $5000 \mathrm{rpm}$ for $20 \mathrm{~min}$ and washed three times with distilled water followed by absolute alcohol. The obtained 
product was calcinated at $500{ }^{\circ} \mathrm{C}$ for $3 \mathrm{~h}$ after drying in an oven.

\subsection{Characterization of $\mathrm{ZnO} \mathrm{NPs}$}

\subsubsection{Phase Analysis}

Phase analysis by X-ray diffraction is done to confirm the phases and impurities present in the calcined chemically and green synthesized $\mathrm{ZnO}$ powders. It involves the irradiation of a monochromatic X-ray beam generated from an X-ray tube on the sample and recording the intensity of the diffracted beam as a function of the goniometer position $(2 \theta)$. It follows and works on the principle based on Bragg's law.

$$
\lambda=2 \mathrm{~d} \sin \theta
$$

Where $\lambda=$ wavelength of the incident X-ray beam, $d=$ interplanar spacing or $d$-spacing, $\theta=$ position of the diffraction angle. Phase analysis is done in the X-Ray powder diffractometer (Rigaku, Japan) fitted with a Ni filter of $0.154 \mathrm{~nm}$. The diffraction patterns were measured using $\mathrm{CuK} \alpha(\lambda=1.5418 \AA)$ radiation generated at a voltage of $40 \mathrm{kV}$ and a current of $40 \mathrm{~mA}$. The samples were scanned in the interval $10^{\circ}<\theta<50^{\circ}$ at a scanning rate $20^{\circ} / \mathrm{min}$ with a step size of $0.05^{\circ}$ in a continuous mode. XRD analysis of the samples was performed using X'pert High Score software in comparison with the reference powder diffraction data given by the Joint Committee on Powder Diffraction Standards (JCPDS).

\subsubsection{Microstructural analysis}

Field emission scanning electron microscope (FESEM) (FEI, Nano Nova, Netherland) along with EDX (energydispersive X-ray) analysis attachment (Bruker, USA) was used to analyze the morphology of the powders. FESEM is a typical electron microscope, which uses a high energy focused beam of electron produced by field emission gun (FEG) for generating an image by just scanning with the beam of electrons that interacts with the surface atoms of the samples to develop relevant information. As the wavelength, of the electron, is very small, a very high magnification can be achieved in field emission electron microscopy. Prior to that, the samples were gold coated for $240 \mathrm{~s}$ in a sputter coater in an Ar atmosphere. The electrons at $15 \mathrm{kV}$ sources were used to develop relevant information about the samples.

\subsection{Determination of antibiotic activity}

Different concentrations of synthesized ZnONPs using both green and chemical methods were evaluated for their antimicrobial activity against the pathogens isolated from milk samples of subclinical mastitis cow. ZnONPs were dissolved in distilled water using a sonicator. The nanoparticles antibiotic activity was evaluated at $650,850,1300$, 1700,1950 and $2500 \mu \mathrm{g} / \mathrm{ml}$ concentrations of $\mathrm{ZnO}$ for each of pathogen isolated from the sample, with both green and chemically synthesized NPs.

The antibiotic activity against each isolate was determined by agar well diffusion method using Muller Hilton agar (HiMedia, India) medium for both types of the nanoparticle synthesized according to CLSI procedure (Wayne, 2009). After the agar was solidified the plates were inoculated and spread with a bacterial suspension of approximately 1-2 X $108 \mathrm{CFU} / \mathrm{ml}$. The wells having a diameter of $6 \mathrm{~mm}$ were prepared. Each of these wells was filled up with $50 \mu \mathrm{L}$ of the $\mathrm{ZnO}$ NPs solution to be tested. Then the inhibition zones around the wells were observed after 24 and $48 \mathrm{~h}$ of incubation at $37^{\circ} \mathrm{C}$.

\subsection{Determination of $\mathrm{MIC}$ and $\mathrm{MBC}$}

The MIC of prepared ZnO NPs against bacteria isolated from subclinical mastitis was determined using a standard broth dilution method (Wayne 2009). The MIC value of the nanoparticle was evaluated at 650, 850, 1300, 1700, 1950 and $2500 \mu \mathrm{g} / \mathrm{ml}$ concentrations of $\mathrm{ZnO}$ for each of pathogen isolated from the sample. Tryptone soya broth (TSB) was used to determine MIC and MBC, as antibacterial assay media. The MIC was identified by observation of turbidity in each tube before and after incubation, the test was done in triplicate. The inhibitory concentration was taken as the lowest concentration that inhibited the growth of each isolated bacteria. The lowest concentration that killed the bacteria was the minimum bactericidal concentration (MBC) and it was determined by sub-culturing $100 \mu \mathrm{L}$ of each sample remaining clear, with no turbidity, in tubes containing $1 \mathrm{~mL}$ of fresh medium, were incubated for $24 \mathrm{~h}$ at $37^{\circ} \mathrm{C}$, and these where compared between the green and chemical method of synthesis of the Nanoparticles.

\section{Results and discussions}

\subsection{Isolation and Identification of pathogens from bovine mastitis milk}

From the milk samples, the two most prominent strains S. aureus and E. coli isolate were identified. On MacConkey agar (HiMedia, India) E. coli appeared smooth, circular pink colonies; it was also Catalase positive and Gram-negative. S.aureus showed hemolysis on blood agar (HiMedia, India), morphologically it was a Grampositive and biochemical test that indicates catalase and coagulase positive. Growth isolates were subcultured on nutrient agar (HiMedia, India), plates at $37^{\circ} \mathrm{C}$ for $24 \mathrm{~h}$ to obtain pure cultures. The bacteria isolated in this investigation are, the more frequently isolated bacterial causes of subclinical mastitis in bovine, this was in 
agreement with the findings from other researches (Günther et al., 2011; Joshi \& Gokhale, 2006; Seyoum, Kefyalew, Abera, \& Abdela, 2018). Because of long-time application of antibiotic for the treatment of mastitis in dairy industries, now days almost all of commonly used drugs are not effective against these pathogens isolated from subclinical mastitis due to antibiotic resistance as described in findings of (Bengtsson et al., 2009; Idriss et al., 2014; Tenhagen, Köster, Wallmann, \& Heuwieser, 2006).

\subsection{Phase Analysis}

The XRD diffractogram of the green and chemically synthesized calcined ZnO powders are shown in Fig 1 . The XRD patterns showed diffraction lines characteristic of $\mathrm{ZnO}$, both present in standards and in the literatures(Goutam et al. 2017; Zak et al. 2013). The peaks well matched with the JCPDS card no 75-0576. It had the hexagonal crystal system with a space group of P63mc. Single and pure phase ZnO powders were observed with the absence of any other impurity phase even in minor quantity. Therefore the calcination temperature was optimized at $500{ }^{\circ} \mathrm{C}$.

\subsection{Microstructural Analysis}

The micrograph of the chemically and green synthesized calcined $\mathrm{ZnO}$ powders is shown in Fig 2. The microstructure as observed under the microscope showed the shape and particle size of the powders. A comparative analysis of both is discussed in this section. The $\mathrm{ZnO}$ nanosized particles were found to be agglomerated. It is observed that the shape of both particles was more or less spherical. Though very few elongated grains were noticed for the chemically synthesized $\mathrm{ZnO}$, the particle size of the chemically synthesized powder was found to be larger than that of the green synthesized powder. The range for the particle size of the synthesized powder was found to be within the nano range of $100 \mathrm{~nm}$.

The corresponding elemental distribution mapping and EDX spectra of the $\mathrm{ZnO}$ powder microstructure chemically and green synthesized is shown in Fig 3 and 4 respectively. It shows the presence and distribution of the different elements such as $\mathrm{O}$ and $\mathrm{Zn}$. The presence of $\mathrm{Au}$ is due to the gold coating done on the powder surface. The presence of only $\mathrm{Zn}$ and $\mathrm{O}$ also confirms the purity of both the synthesized powder which complements the XRD analysis as well.

\subsection{Antibiotic activity}

The antibiotic activity of the nanoparticle was investigated by measuring the size of the inhibition zone. The nanoparticle, at the tested concentrations, showed different levels of antibiotic activity against each bacterial strain. Antimicrobial activity of ZnO NPs against broad spectrum microorganism was reported (Jones et al. 2008) and it has been used in biomedical and therapeutic research in human medicine, its application in the field of veterinary medicine would be effective in treating diseases like mastitis as suggested in this work. Both green and chemically synthesized $\mathrm{ZnO}$ NPs have shown almost the same level of antibiotic activity (Fig 5 and Fig 6), showing that, no significant difference in antibiotic activity value between them against the pathogens isolated from subclinical mastitis (Fig 7 and Fig 8). The results indicated that the diameter of the zone of inhibition increases with the concentration of the nanoparticle.

\subsection{Determination of $\mathrm{MIC}$ and $\mathrm{MBC}$}

The test tubes used for MIC were examined for turbidity after 24 hours of incubation at $37^{\circ} \mathrm{C}$. The turbidity was different between both bacterial species. All the tested concentrations of ZnONPs, including the minimum concentration at $650 \mu \mathrm{g} / \mathrm{ml}$ did not show any turbidity for $S$. aureus, that it prevented the growth of the bacteria. The concentration of ZnONPs starting from $850 \mu \mathrm{g} / \mathrm{ml}$ did not show turbidity for $E$. coli bacteria. From these outcomes we concluded, that the MIC is $650 \mu \mathrm{g} / \mathrm{ml}$ and $850 \mu \mathrm{g} / \mathrm{ml}$ for $S$. aureus and E. coli respectively for both green and chemical methods of nanoparticle synthesis methods (Table.1). The MBC value is found to be $650 \mu \mathrm{g} / \mathrm{ml}$ and $1700 \mu \mathrm{g} / \mathrm{ml}$ for both $S$. aureus and E.coli respectively for both synthesis methods . S. aureus was susceptible for lower concentration of ZnO NPs than E. coli which supported the reports by (Alekish, Ismail, Albiss, \& Nawasrah, 2018; Khalid, Khan, Ul-Islam, Khan, \& Wahid, 2017; Liu et al., 2009) that Gram-positive bacteria were more sensitive to the $\mathrm{ZnO}$ Nanoparticle than Gram-negative bacteria. The inhibitory efficacy of $\mathrm{ZnO}-\mathrm{NPs}$ is dependent on its concentration and size (Memon et al., 2013). The wound healing activities of ZnO-NPs were shown by the work of (Kumar et al., 2019; Sharma et al., 2007), this means that ZnO NPs have anti-inflammatory activity, since mastitis is inflammation the combined anti-inflammatory and antibiotic activity of the nanoparticle would be effective in the treatment of mastitis.

\section{CONCLUSION}

In conclusion, ZnONPs was synthesized using green and chemical methods of synthesis and characterized by FTIR, powder XRD. The antibiotic activity of the nanoparticle against common causes of subclinical bovine mastitis was investigated as an alternative treatment approach for mastitis in the dairy cow. The results of this 
study indicate the potential anti-bacterial effects of $\mathrm{ZnO}$ NPs against $S$. aureus and E. coli isolated from bovine subclinical mastitis at concentrations of $650 \mu \mathrm{g} / \mathrm{ml}$ and $850 \mu \mathrm{g} / \mathrm{ml}$, respectively. Isolated pathogens which are $S$. aureus and E. coli strains were susceptible to ZnO NPs and there is no significant difference between the efficacy of green and chemically synthesized ZnO NPs. As subclinical Mastitis is inflammation caused commonly by bacteria, the antibiotic and wound healing activities of ZnO NPs can facilitate effective treatment of mastitis in dairy. This study is limited to the effect of the nanoparticles on common bacterial causes of subclinical bovine mastitis and it is conducted invitro; further studies are required to know the effect on other causes of mastitis as well as clinical trials are required.

\section{Acknowledgements}

The authors thankfully acknowledge the extended support of Dr.B.Jaya Kumar Singh, Department of biotechnology for editing the paper and constructive comments, and Dr. Ritwik Sarkar, Professor of Department of Ceramic Engineering, National Institute of Technology, Rourkela during material characterization. This research did not receive any specific grant from funding agencies in the public, commercial, or not-for-profit sectors.

\section{Conflict of interest}

The authors declare no conflict of interest in this work.

\section{Authors' contributions}

Rupita Ghosh corresponding author, involved in the study design. Zerihun Beyene involved in the project implementation, editing, and major revisions of manuscript.

\section{References}

Bradley A, Leach K, Breen J, Green L, and Green M. 2007. Survey of the incidence and aetiology of mastitis on dairy farms in England and Wales. Veterinary Record 160, 253-258.

El-Jakee J, Hableel H, Kandil M, Hassan O, Khairy EA, and Marouf S. 2013. Antibiotic resistance patterns of isolated from mastitic cows and ewes in Egypt. Global Vet 10, 264-270.

Ghorbani HR, Mehr FP, Pazoki H, and Rahmani BM. 2015. Synthesis of ZnO nanoparticles by precipitation method. Oriental Journal of Chemistry 31, 1219-1221.

Goutam SP, Yadav AK, and Das AJ. 2017. Coriander extract mediated green synthesis of zinc oxide nanoparticles and their structural, optical and antibacterial properties. Journal of Nanoscience and Technology, 249-252.

Gunay A, and Gunay U. 2008. Effects of clinical mastitis on reproductive performance in Holstein cows. Acta Veterinaria Brno 77, 555-560.

Hassan A, Oraby N, Mohamed AA, and Mahmoud H. 2014. The possibility of using Zinc Oxide nanoparticles in controlling some fungal and bacterial strains isolated from buffaloes. Egypt J Appl Sci 29, 58-83.

Jin T, Sun D, Su J, Zhang H, and Sue HJ. 2009. Antimicrobial efficacy of zinc oxide quantum dots against Listeria monocytogenes, Salmonella enteritidis, and Escherichia coli O157: H7. Journal of food science 74, M46M52.

Jones N, Ray B, Ranjit KT, and Manna AC. 2008. Antibacterial activity of ZnO nanoparticle suspensions on a broad spectrum of microorganisms. FEMS microbiology letters 279, 71-76.

Kampeerapappun P. 2019. Effect of zinc oxide loaded polyester fibers on the color, mechanical properties and antibacterial action of woven fabric. Journal of Metals, Materials and Minerals 28.

Kumar AK, Saila ES, Narang P, Aishwarya M, Raina R, Gautam M, and Shankar EG. 2019. Biofunctionalization and biological synthesis of the $\mathrm{ZnO}$ nanoparticles: The effect of Raphanus sativus (white radish) root extract on antimicrobial activity against MDR strain for wound healing applications. Inorganic Chemistry Communications 100, 101-106.

Lutz W, Butz WP, and Samir K. 2017. World population \& human capital in the twenty-first century: An overview: Oxford University Press.

Memon J, Yang Y, Kashif J, Yaqoob M, Buriro R, Soomro J, Liping W, and Hongjie F. 2013. Genotypes, Virulence Factors and Antimicrobial Resistance Genes of Staphylococcus aureus Isolated in Bovine Subclinical Mastitis from Eastern China. Pakistan Veterinary Journal 33.

Middleton JR, Saeman A, Fox LK, Lombard J, Hogan JS, and Smith KL. 2014. The National Mastitis Council: a global organization for mastitis control and milk quality, 50 years and beyond. Journal of mammary gland biology and neoplasia 19, 241-251.

Mohanraj R. 2017. Antimicrobial activities of metallic and metal oxide nanoparticles from plant extracts. In: Antimicrobial Nanoarchitectonics, Elsevier, 83-100.

Raguvaran R, Manuja A, and Manuja BK. 2015. Zinc oxide nanoparticles: opportunities and challenges in veterinary sciences. Immunome Research 11, 1. 
Reddy KM, Feris K, Bell J, Wingett DG, Hanley C, and Punnoose A. 2007. Selective toxicity of zinc oxide nanoparticles to prokaryotic and eukaryotic systems. Applied physics letters 90, 213902.

Sharma N, Maiti S, and Sharma KK. 2007. Prevalence, etiology and antibiogram of microorganisms associated with Sub-clinical mastitis in buffaloes in Durg, Chhattisgarh State (India). International Journal of Dairy Science 2, 145-151.

Sharma N, Batoo AS, Huma ZI, Kour S, Misri J, and Hussain K. 2017. Impact of mastitis on reproductive performance in dairy animals: A review. Theriogenology Insight 7, 41.

Stevens M, Piepers S, and De Vliegher S. 2019. The effect of mastitis management input and implementation of mastitis management on udder health, milk quality, and antimicrobial consumption in dairy herds. Journal of dairy science 102, 2401-2415.

Sun H-Z. 2018. Feedomics: promises for food security with sustainable food animal production. TrAC Trends in Analytical Chemistry.

Wayne P. 2009. Methods for Dilution Antimicrobial Susceptibility Tests for Bacteria that Grow Aerobically; CLSI document M07-A7. Approved Standard Eighth Edition ed: Clinical and Laboratory Standards Institute.

Xie Y, He Y, Irwin PL, Jin T, and Shi X. 2011. Antibacterial activity and mechanism of action of zinc oxide nanoparticles against Campylobacter jejuni. Appl Environ Microbiol 77, 2325-2331.

Zak AK, Majid WA, Mahmoudian M, Darroudi M, and Yousefi R. 2013. Starch-stabilized synthesis of ZnO nanopowders at low temperature and optical properties study. Advanced Powder Technology 24, 618-624.

Table- I : The MIC and MBC values $(\mu \mathrm{g} / \mathrm{ml})$ of ZnO-NPs against $S$. aureus and E. coli strains isolated from bovine affected with subclinical mastitis.

\begin{tabular}{lllc}
\hline $\begin{array}{l}\text { Method of zinc oxide nano particle } \\
\text { synthesis }\end{array}$ & Bacterial isolates & MIC & MBC \\
\hline Green synthesis & S. aureus & $650 \mu \mathrm{g} / \mathrm{ml}$ & $650 \mu \mathrm{g} / \mathrm{ml}$ \\
& E. coli & $850 \mu \mathrm{g} / \mathrm{ml}$ & $1700 \mu \mathrm{g} / \mathrm{ml}$ \\
Chemical synthesis & S. aureus & $650 \mu \mathrm{g} / \mathrm{ml}$ & $650 \mu \mathrm{g} / \mathrm{ml}$
\end{tabular}

Note : MIC=Minimum inhibitory concentration, $\mathrm{ZnO}$ NPs $=$ Zinc oxide nanoparticles, S. aureus $=$ Staphylococcus aureus, E. coli $=$ Escherichia coli

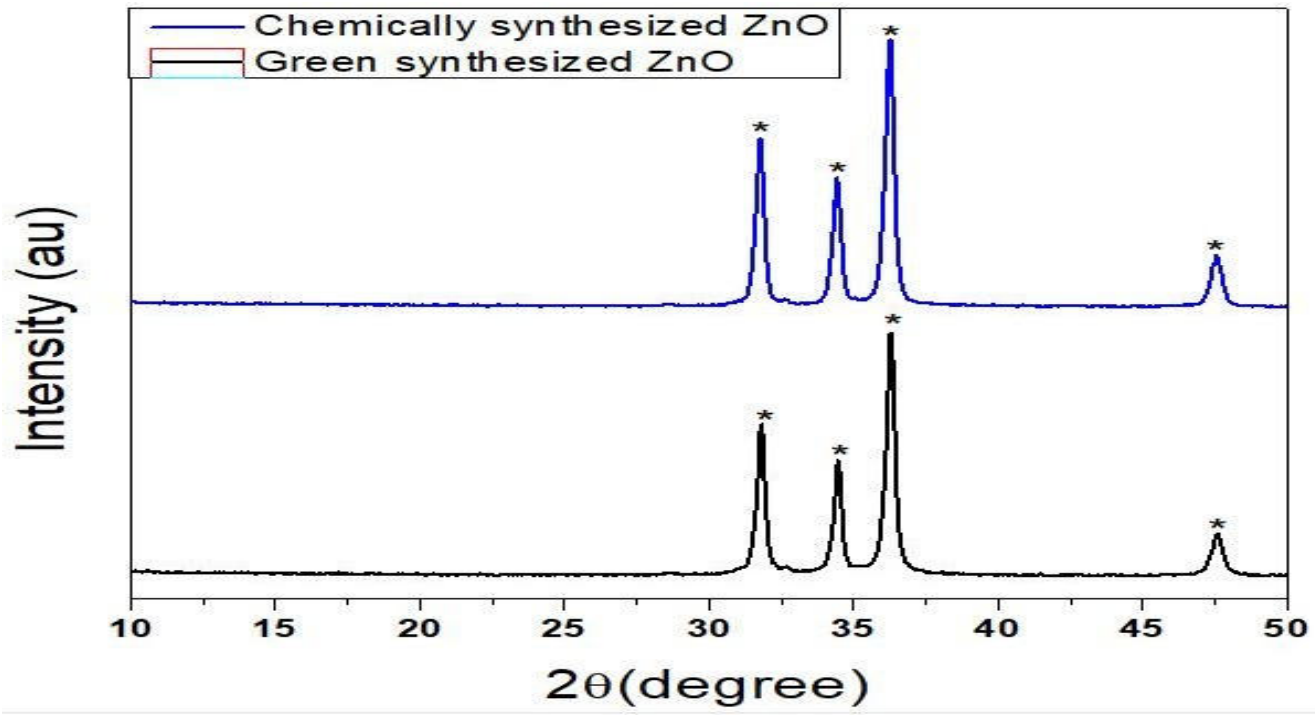

Fig: 1 . Phase analysis of green and chemically synthesized $500{ }^{\circ} \mathrm{C}$ calcined $\mathrm{ZnO}$ powders 

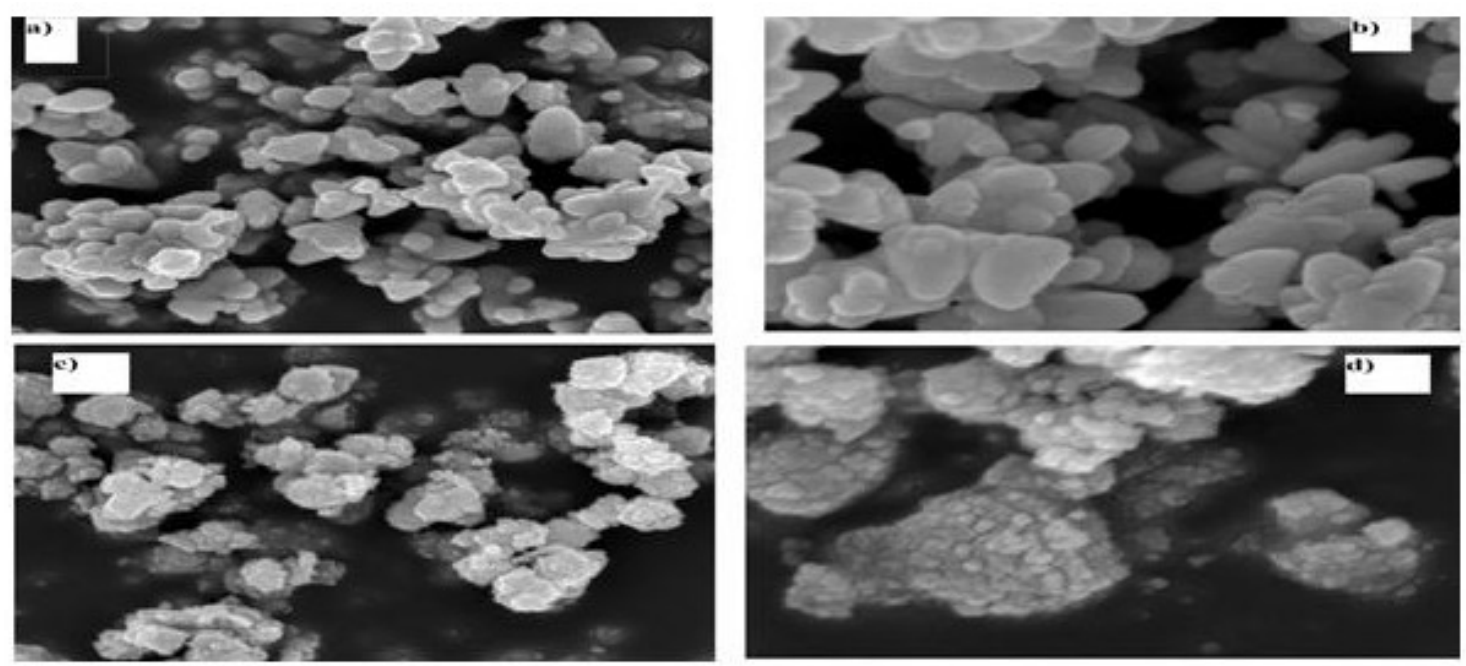

Fig: 2. Micrograph of chemically synthesized $\mathrm{ZnO}$ particles at (a) lower magnification (b) higher magnification; green synthesized $\mathrm{ZnO}$ particles at (c) lower magnification (d) higher magnification
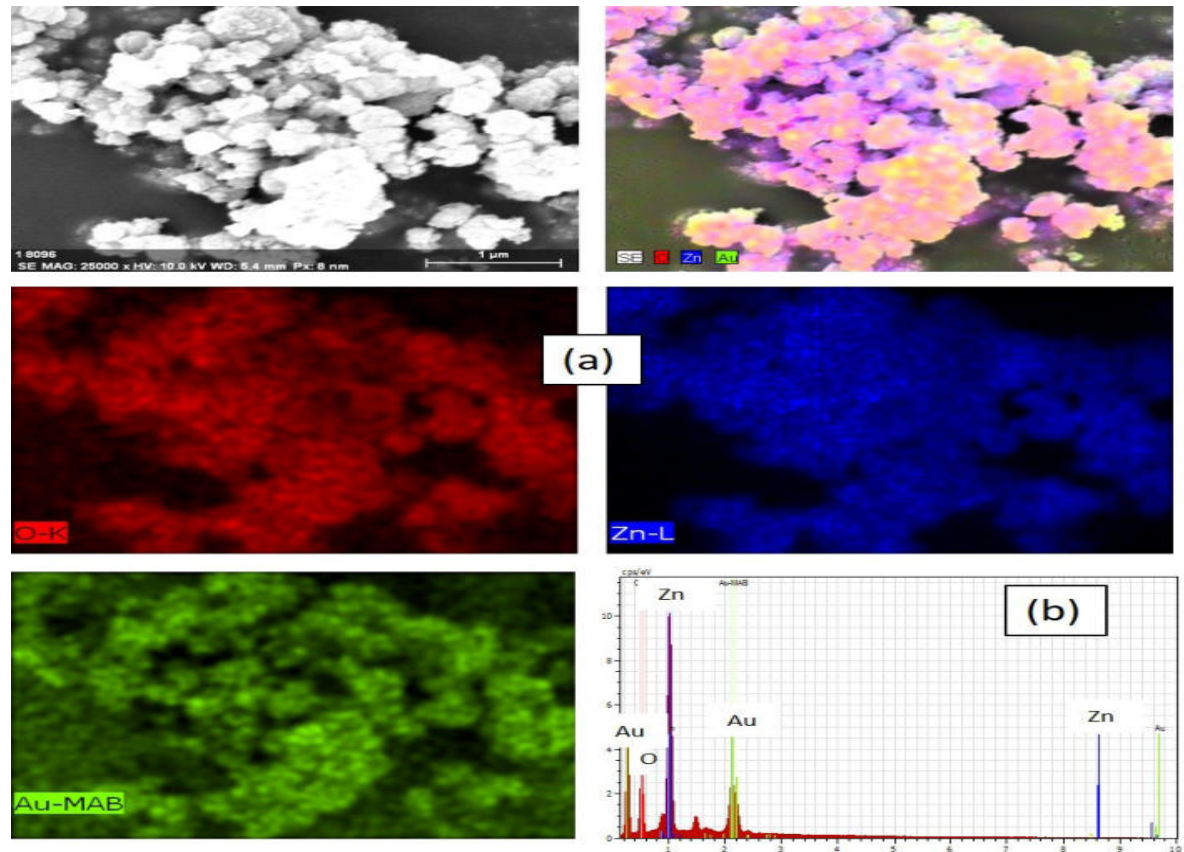

Fig: 3. (a) Elementary mapping of $500{ }^{\circ} \mathrm{C}$ calcined chemically synthesized $\mathrm{ZnO}$ powder showing the distribution of elements such as $\mathrm{O}$ and $\mathrm{Zn}$, (b) EDX spectra of green synthesized $\mathrm{ZnO}$ powder. 

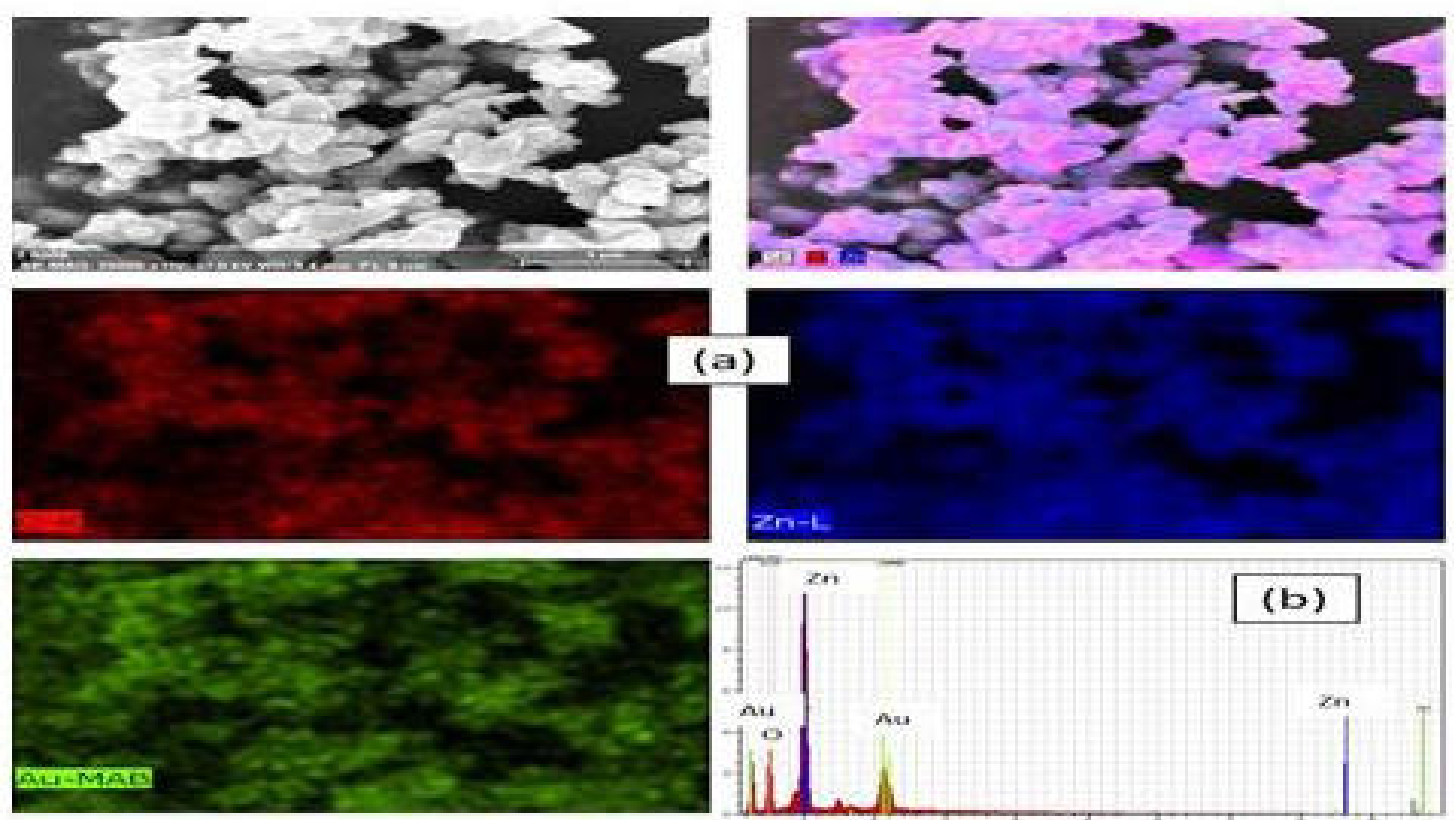

Fig: 4. (a) Elementary mapping of $500{ }^{\circ} \mathrm{C}$ calcined green synthesized $\mathrm{ZnO}$ powder showing distribution of elements such as $\mathrm{O}$ and $\mathrm{Zn}$, (b) EDX spectra of green synthesized $\mathrm{ZnO}$ powder.

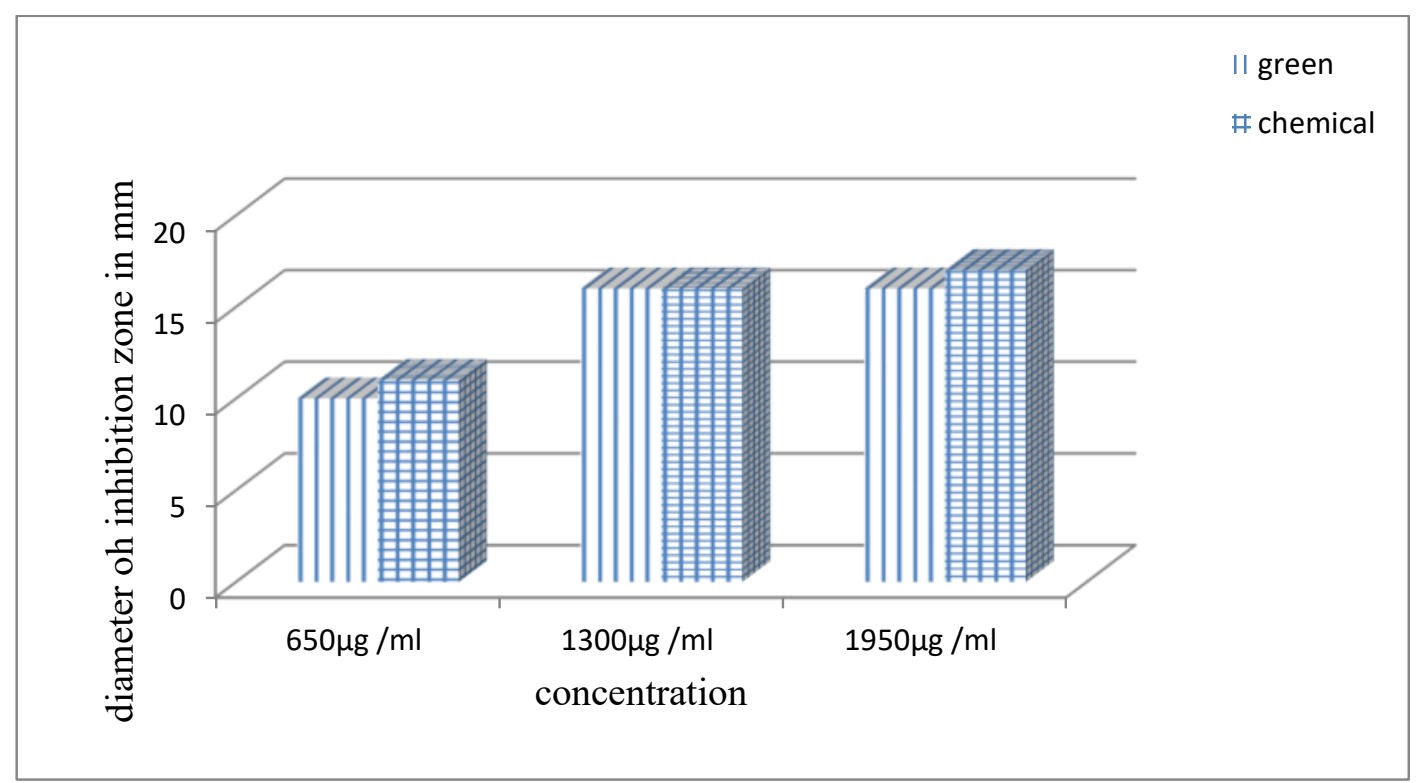

Fig: 5. Comparison of zone of inhibition of green and chemical methods in diameter (mm) against $S$. aureus at 650,1300 and $1950 \mu \mathrm{g} / \mathrm{ml}$. 


\section{II green \\ \pm chemical}

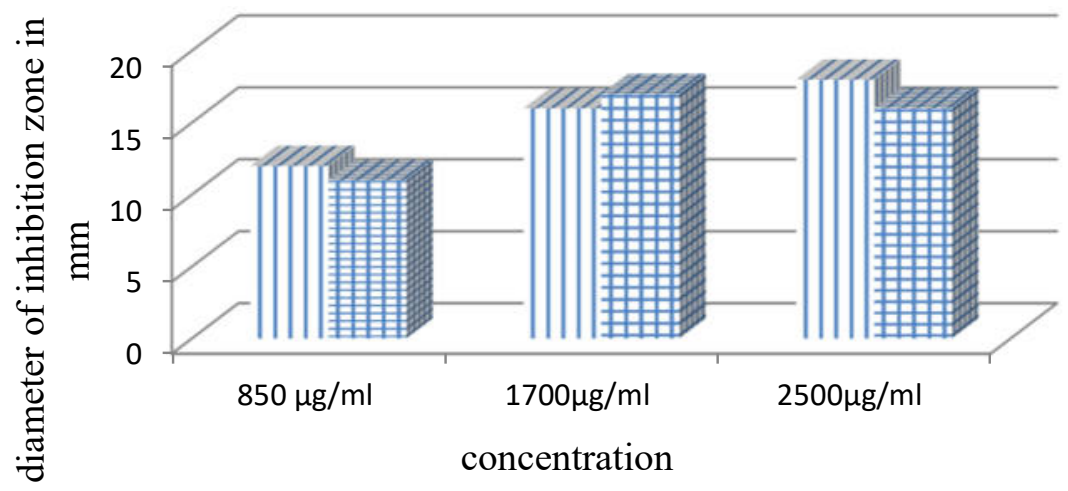

Fig: 6. Comparison of zone of inhibition of green and chemical methods in diameter (mm) against E. coli at 850 , 1700 and $2500 \mu \mathrm{g} / \mathrm{ml}$

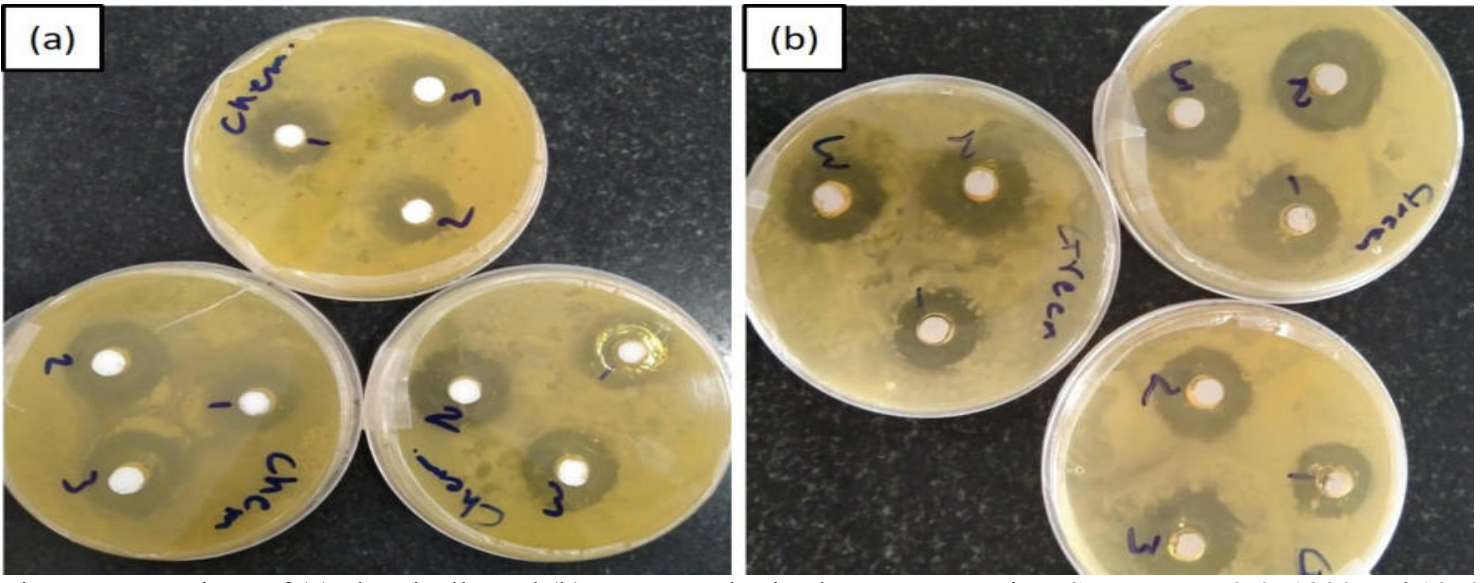

Fig: 7. Comparison of (a) chemically and (b) green synthesized ZnO NPs against S. aureus at 650, 1300 and 1950 $\mu \mathrm{g} / \mathrm{ml}$.

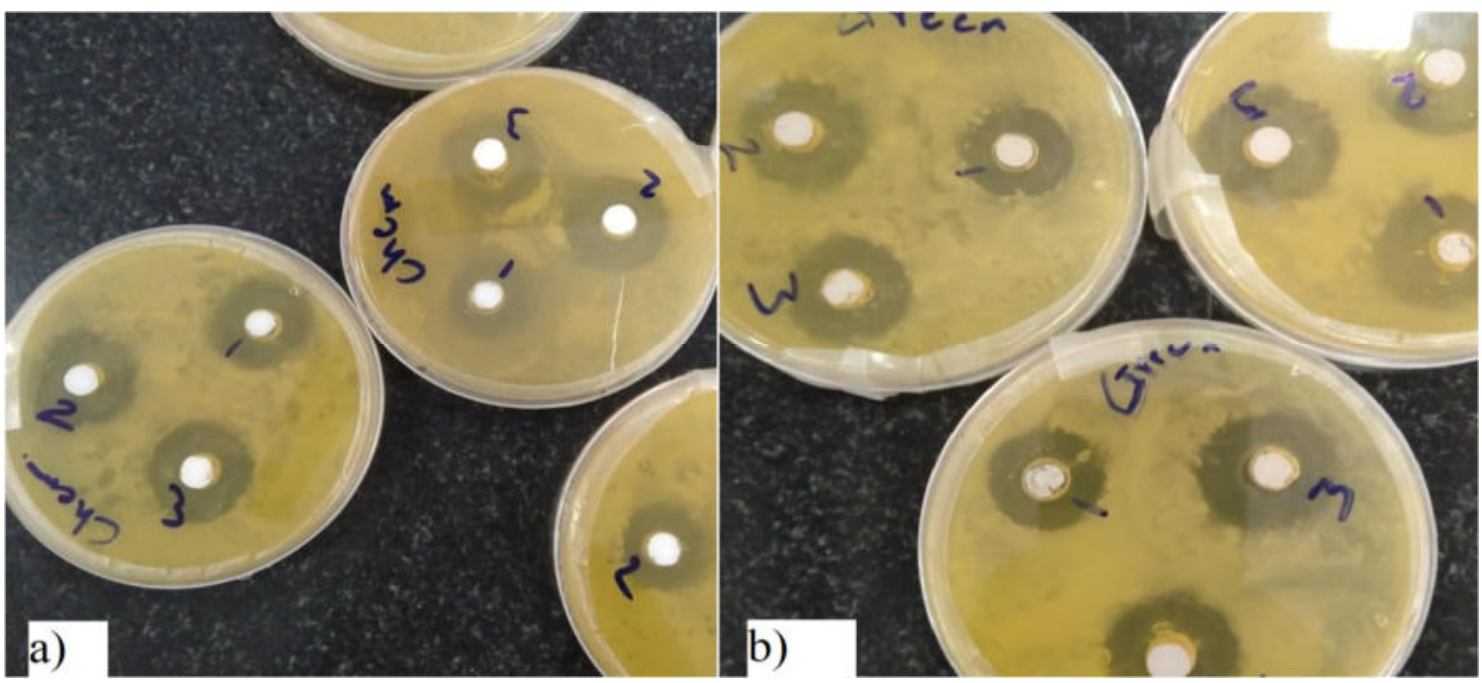

Fig: 8. Comparison of (a) chemically and (b) green synthesized ZnO NPs against E. coli at 850, 1700 and 2500 $\mu \mathrm{g} / \mathrm{ml}$ 